\title{
Passive RFID Tag for Railway Application
}

\author{
Shreine Abd El-Rahman', Ahmed Attiya', Hossam El-Deen Mamoud², Hala Abd-El Kader² \\ ${ }^{1}$ Electronics Research Institute, Giza, Egypt \\ ${ }^{2}$ Shoubra Faculty of Engineering, Benha University, Cairo, Egypt \\ Email: eng_sherine@eri.sci.eg, attiya@eri.sci.eg,dr.housammahmoud@yahoo.com,hala.mansour@gmail.com
}

How to cite this paper: El-Rahman, S.A., Attiya, A., Mamoud, H.E.-D. and Kader, H.A.-E. (2018) Passive RFID Tag for Railway Application. Open Journal of Antennas and Propagation, 6, 15-24.

https://doi.org/10.4236/ojapr.2018.62002

Received: April 1, 2018

Accepted: June 1, 2018

Published: June 4, 2018

Copyright (C) 2018 by authors and Scientific Research Publishing Inc. This work is licensed under the Creative Commons Attribution International License (CC BY 4.0). http://creativecommons.org/licenses/by/4.0/

\section{Open Access}

\begin{abstract}
Passive RFID tags based on narrow band absorbers are proposed for railway applications. The tags consist of absorbing tiles of size $30 \times 30 \mathrm{~cm}^{2}$. The designs of these narrow band absorbers are presented based on infinite array approximation by using periodic boundary conditions. Then, the radar cross sections (RCS) of finite tiles of these designed absorbers are compared with the corresponding RCS of a conduction plate of the same size of the tiles. The difference between the RCS of the absorbing tiles and the conducting tiles corresponds to the RFID digit " 1 " or " 0 ". An experiential verification for a sample of these narrow band absorbers is presented based on measuring a finite tile inside a transverse electromagnetic (TEM) cell. The design of this TEM cell is also discussed in detail.
\end{abstract}

\section{Keywords}

RFID Tag, TEM Cell, Absorbers, Periodic Structures

\section{Introduction}

Radio Frequency Identification (RFID) is a technique that combines radio frequency with computer system to introduce a wireless automatic identification system [1]. RFID systems are being applied to many applications. Generally, RFID system consists of a reader, an RF module, an antenna and a tag [1]. RFID tag can be classified into two main categories: active and passive namely. The main difference between passive and active tags is that active RFID tag is powered through an internal power source; whereas passive RFID tag responses to the incident RF energy transferred from the reader to the tag when the tag is passing through the reader [1] [2].

Identification process for railway application has a significant importance in many cases like determining the location and the speed of the railway vehicles. Railway vehicle identification system consists of information collection, 
processing and transmission subsystems as shown in Figure 1. RFID system is a key component of the railway vehicle identification system. In Railway Vehicle Identification system, each vehicle is equipped with a unique tag which is mounted on the vehicle. This tag contains the identification data of this vehicle. The tag has its response when it passes by the reader. The readers are usually located at fixed points separated by equal distances. The RF reader is designed to collect the vehicle identity sent from the Tags. The Reader is connected to a computer control system. Once the Reader receives the vehicle identity from the Tag, the Reader reports the associated vehicle arrival or departure information at this location to the control system. The control system then captures this data for further processing [3]-[9].

General RFID tracking system for vehicles and their main applications are discussed in [10]. These systems include traffic signal timings, congestions on the road and theft of vehicles. The difference in the case of railway application is that the train travels on a specified constant way while other vehicles have different directions and locations. This property of railway vehicles simplifies the implementation of RFID in this application. Different examples of RFID systems for railway application are discussed in [3]-[9]. Different problems are also discussed in these cases like high speed train, data collision and insufficient reading time. An example for this RFID system is active RFID tag which uses an inductive coil with the tag and a permanent magnet on the railway to activate the tag while the train is moving with respect to the fixed magnet. However, the operation of this system depends on the speed of the train at the reading point. Thus, the validity of this system may not be assured for all speeds. On the other hand, a fully passive printable chipless RFID system based on multi-resonators is presented in [10] [11] [12]. This chipless tag uses the amplitude and phase of the spectral signature of a multi-resonator circuit. The amplitude and phase of the backscattered field from this tag provide the corresponding data bits. In this case, the tag consists of microstrip multi-resonators and cross-polarized UWB (Ultra Wide Band) transmitting and receiving antennas. In this case, the used UWB is the unlicensed FCC UWB in the frequency range from 3.1 to $10.6 \mathrm{GHz}$. However, this tag is usually very small for large targets like trains. Also, it may not be suitable for high speed vehicle since the available reading time is very short.

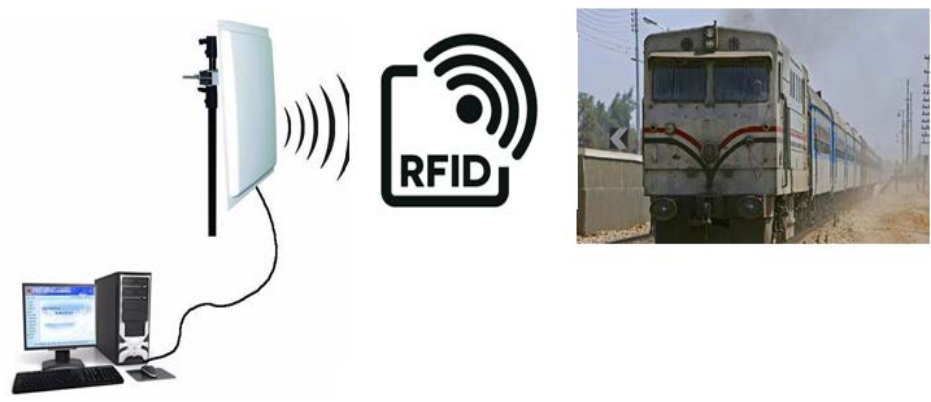

Figure 1. Railway RFID system block diagram. 
In this paper, we present a new idea for a passive tag which is suitable for large targets. The idea of the proposed tag is based on attaching narrow band absorbing tiles on the side wall of the train. These absorbing tiles play the same role of the multiple resonators but with larger size which is suitable for the railway application.

This paper is organized as follows. Section 2 presents the basic design of narrow band absorbers which are used as the elements of the proposed passive RFID tag. These narrowband absorbers are composed of periodic patches on a grounded lossy dielectric slab. These periodic structures are designed by simulating a single element in periodic boundary conditions. The designed elements are used to simulate finite size tiles which are used as absorbing tiles on the train. The radar cross section (RCS) of these finite tiles is compared with the corresponding RCS of PEC tiles of the same size. The difference between these two RCS values represents the obtained data by the reader. In Section 3, an experimental verification of a sample of these narrow band absorbers is presented by using TEM cell. Finally, Section 4 presents the conclusion.

\section{Design Narrowband Absorbers for RFID Application}

\subsection{Unit Cell of Narrow Band Absorber}

The proposed RFID tag is composed of multiple narrow band absorbers. These absorbers are based on periodic patches on a lossy grounded dielectric slab [13] [14] [15]. These patches are also covered with a superstrate. This superstrate is used as a protection layer to the printed patches because of the nature railway application. In this section, the design of different narrow band absorbers based on different shapes of the patches is studied. These shapes include hexagonal, square and circular patches. Both the substrate and the superstrate are FR-4 with $\varepsilon_{r}=4.5$ and loss tangent $\tan \delta=0.019$. Their thicknesses are the same $h_{1}=h_{2}=$ $0.8 \mathrm{~mm}$. The unit cell of the periodic structure is assumed to be square of size 30 $\times 30 \mathrm{~mm}^{2}$ as shown in Figure 2. The unit cell is designed by using ANSYS HFSS - software. The infinite array structure is simulated by using a single cell in periodic boundary conditions. Figure 3 shows the results for the different shapes of patches as functions of their dimensions.

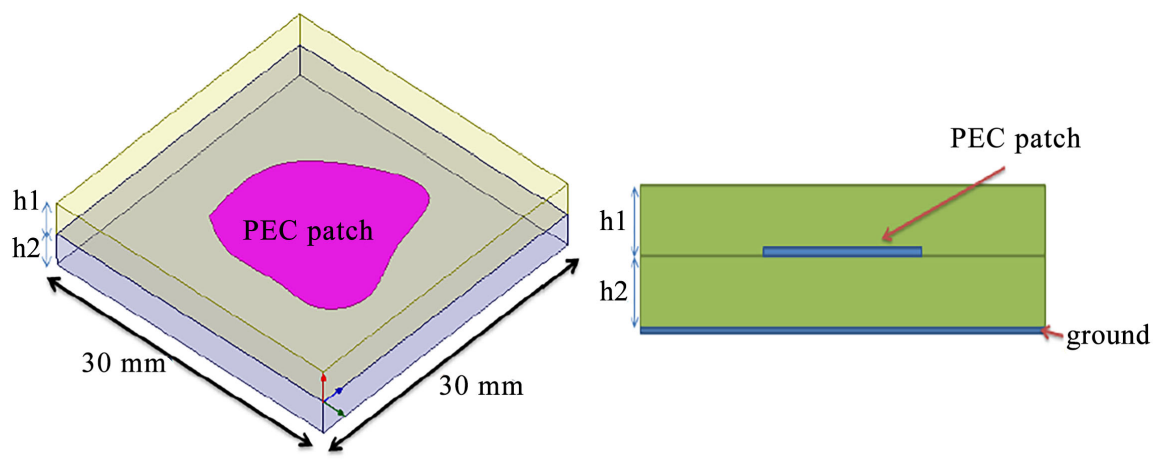

Figure 2. General Configuration of a unit cell. 


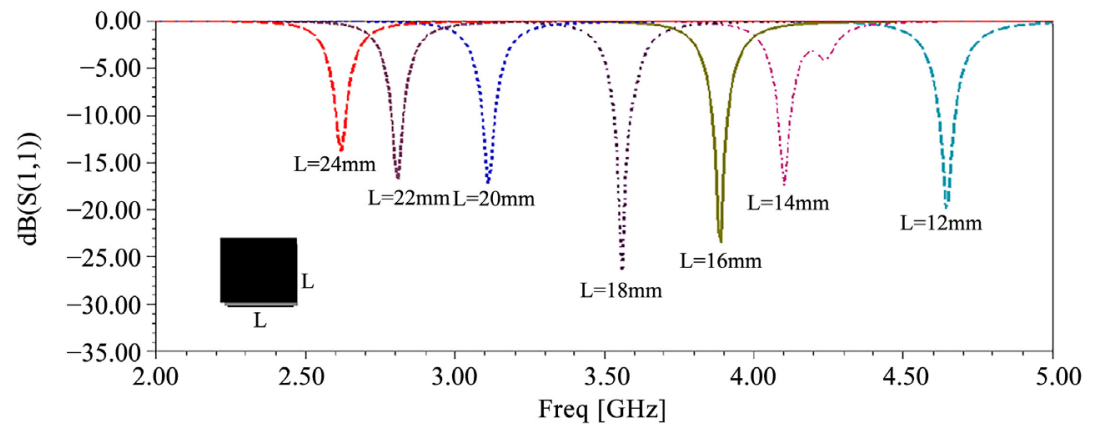

(a)

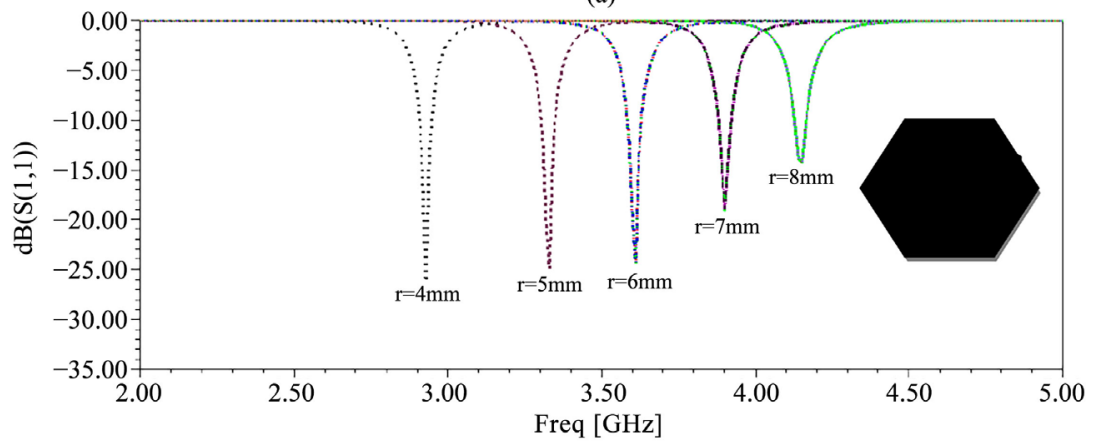

(b)

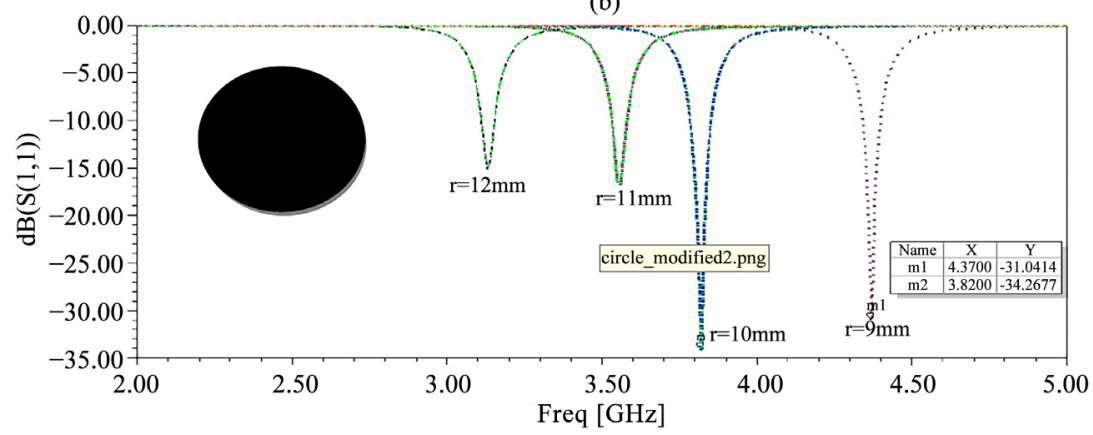

(C)

Figure 3. (a) Square unit cell results at different frequencies; (b) Hexagon unit cell results at different frequencies; (c) Circular unit cell results at different frequencies.

In this case, each absorbing frequency can be used as a different digit in RFID system as in the case of multi-resonator RFID tag [10] [11]. It can be noted the reflection coefficients of the proposed absorbers at the absorbing frequencies for the case of square patches are around $-20 \mathrm{~dB}$ in most cases. These values can be improved to be less than $-25 \mathrm{db}$ in Hexagonal patches and to be less than -30 $\mathrm{dB}$ in circular patches in some cases. Thus, it can be concluded that different shapes are suitable for different frequencies. As an example, square patches are suitable for frequency 3.56 and $3.89 \mathrm{GHz}$, hexagonal patches are suitable for frequencies 2.93 and $3.33 \mathrm{GHz}$ and the circular patches are more suitable for the frequencies 4.37 and $3.58 \mathrm{GHz}$ as shown in Figure 3.

\subsection{RCS of Finite Absorber Tiles}

In practical case, finite absorber tiles are used. Thus, the previous simulation of 
infinite array structure by simulating a single element in periodic boundary conditions can only be used as a starting point for the design of finite absorber tile [16]. The proposed tiles have dimensions $30 \times 30 \mathrm{~cm}^{2}$ as shown in Figure 4 for different patch configurations. In the proposed application, the corresponding digit of each tile is " 1 " or " 0 " based on the presence of the absorber tile or not. This difference can be detected by comparing the RCS of the tile to the corresponding RCS of a PEC tile of the same size. This is mainly the function of the reader which should be fixed at a constant distance from the railway.

Figure 5 shows the RCS of samples of these finite absorbers at their corresponding resonance absorbing frequencies compared to the RCS of PEC plate of the same size at these frequencies. It can be noted that difference between the RCS of the finite absorber tile and the RCS of the PEC is about $12 \mathrm{~dB}$ for square patches, $8 \mathrm{~dB}$ for hexagonal patches and $14 \mathrm{~dB}$ for circular patches. It can be noted that these finite absorber tiles can be designed to introduce RCS differences more that $10 \mathrm{~dB}$ compared with PEC tiles for most cases. This $10 \mathrm{~dB}$ is quite enough to discriminate between the absorber tile and the PEC tile. Thus, it can be used as an RFID digit. In the following section, an experimental verification for the circular-patch absorber is presented as an example for these finite tiles.

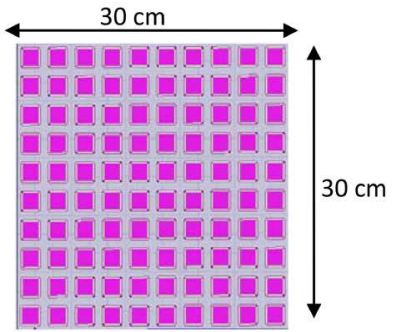

(a)

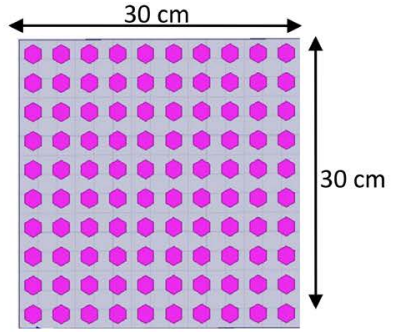

(b)

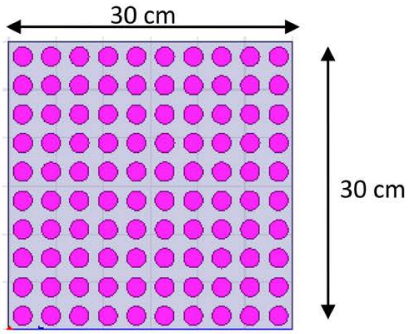

(c)

Figure 4. Finite absorber tiles. (a) Square array; (b) Hexagonal array; (c) Circular array.

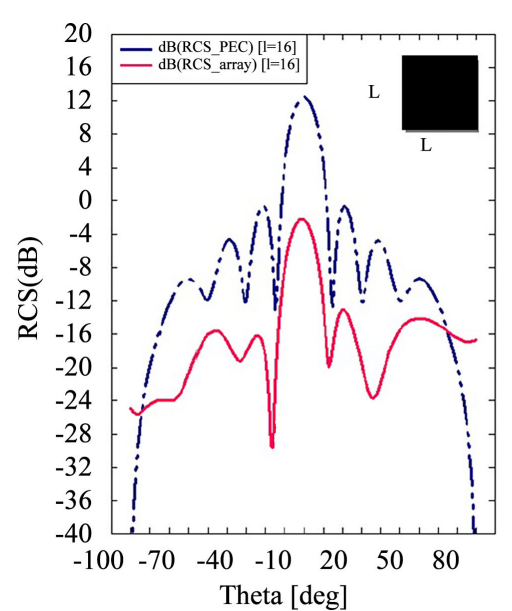

(a)

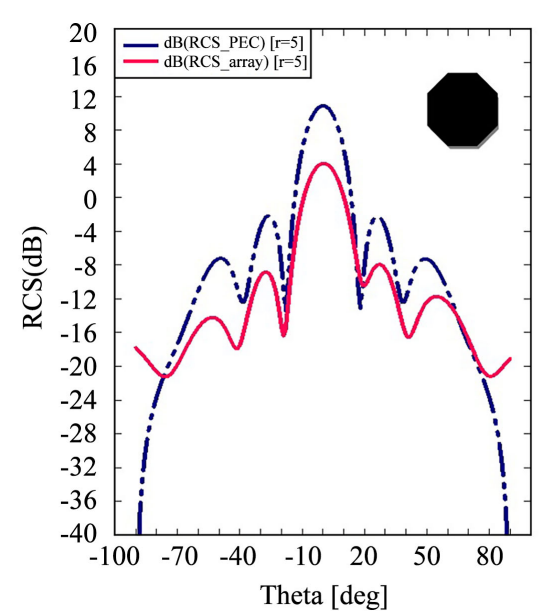

(b)

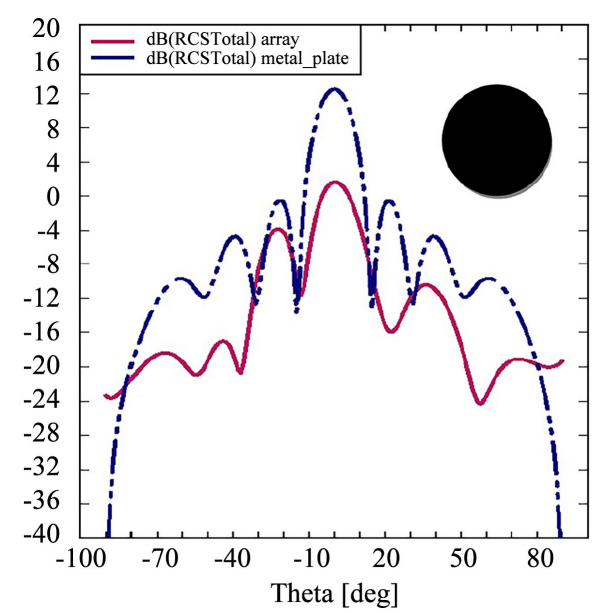

(c)

Figure 5. Comparison between RCS of finite tile absorbers of size $30 \times 30 \mathrm{~mm}^{2}$ and PEC tile for different patches. (a) Comparison between RCS of square-patches absorber tile and PEC tile at $3.56 \mathrm{GHz}$; (b) Comparison between RCS of hexagunal-patches absorber tile and PEC tile at $3.33 \mathrm{GHz}$; (c) Comparison between RCS of circular-patches absorber tile and PEC tile at $4.35 \mathrm{GHz}$. 


\section{Experimental Verification of Narrow Band Absorber Tile}

In this section an example of the above designed absorber tiles is verified experimentally. To synthesize an equivalent incident plane wave, we used a TEM cell [16] [17]. The TEM cell consists of two tapered transmission line sections connected to a parallel plate waveguide as shown in Figure 6. The height of the parallel plate waveguide is chosen to be the same as the periodic cell of the absorber tile which is $3 \mathrm{~cm}$.

This parallel plate waveguide can be used to represent equivalent periodic structure in the perpendicular direction to the parallel plates by applying the image theory. However, the structure along the width of the parallel plate waveguide would be finite. The dimensions of the proposed TEM cell are designed and optimized numerically by using HFSS. The final dimensions of the TEM cell are as shown in Figure 6. Figure 7 shows the simulated electric field distribution along the designed TEM cell at $4.35 \mathrm{GHz}$. It can be noted that the field distribution at the center of the parallel plate waveguide is nearly uniform plane wave. Figure 8 shows the fabricated TEM cell. The cell is fabricated by using a copper plate of thickness $0.5 \mathrm{~mm}$. To support the parallel plate part, a layer of foam with a thickness $3 \mathrm{~cm}$ is inserted as shown in Figure 8. The dielectric constant of this foam layer is nearly 1.07 .

This layer was also included in the simulation. A slight slit is presented in the foam layer as shown in Figure 8. This slit is used to insert or remove the absorbing sheet as shown in the following results. Figure 9 shows a comparison between the simulated and measured reflection coefficient of the TEM cell without any sample inside it.

Figure 10 shows the simulated comparison between the $S_{11}$ for the TEM cell with and without the absorbing tile. In this case the absorbing tile is based on circular patches with radii $\mathrm{R}=10 \mathrm{~mm}$ which satisfy absorption at $4.35 \mathrm{GHz}$ as discussed in Figure 3(c). The tile in this case is composed of only four patches as shown in Figure 11. These four patches are equivalent to infinite array in the $z$-direction inside the TEM cell by applying the image theory. It can be noted from Figure 10 that the simulation results show a significant reduction more than $20 \mathrm{~dB}$ in the measured reflection coefficient at the designed absorption frequency.

This result is quite consistent with the simulation result of the corresponding infinite array structure in Figure 3(c). Figure 12 shows the comparison of the measured results of $S_{11}$ with and without the absorbing tile. Excellent agreements between measured results shown in Figure 12 and simulated results shown in Figure 10 are obtained. This experimental result represents a good verification for the mentioned theory in Section 3.

\section{Conclusion}

A new RFID tag based on narrowband absorbers is proposed for railway application. The absorbers are based on periodic patches on a grounded lossy substrate 


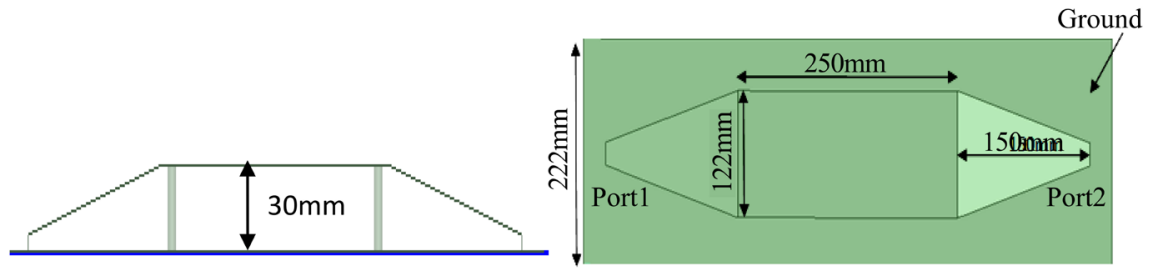

Figure 6. TEM Design (a) side view; (b) top view.

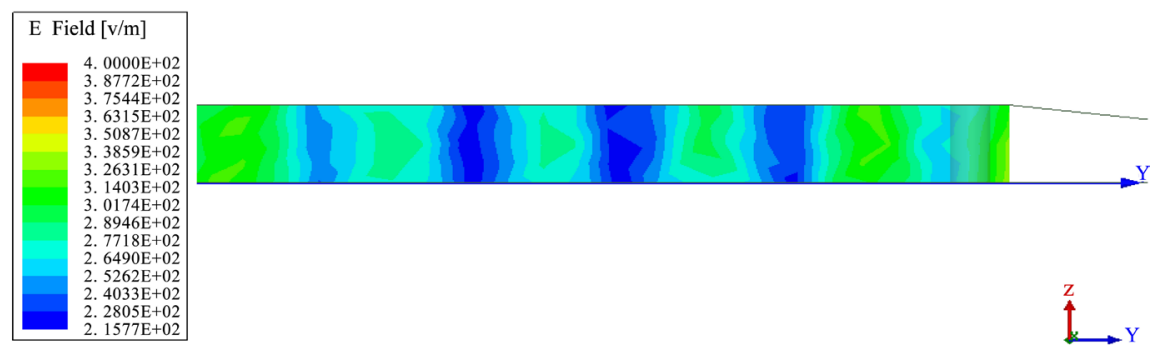

Figure 7. Field plot of empty TEM.

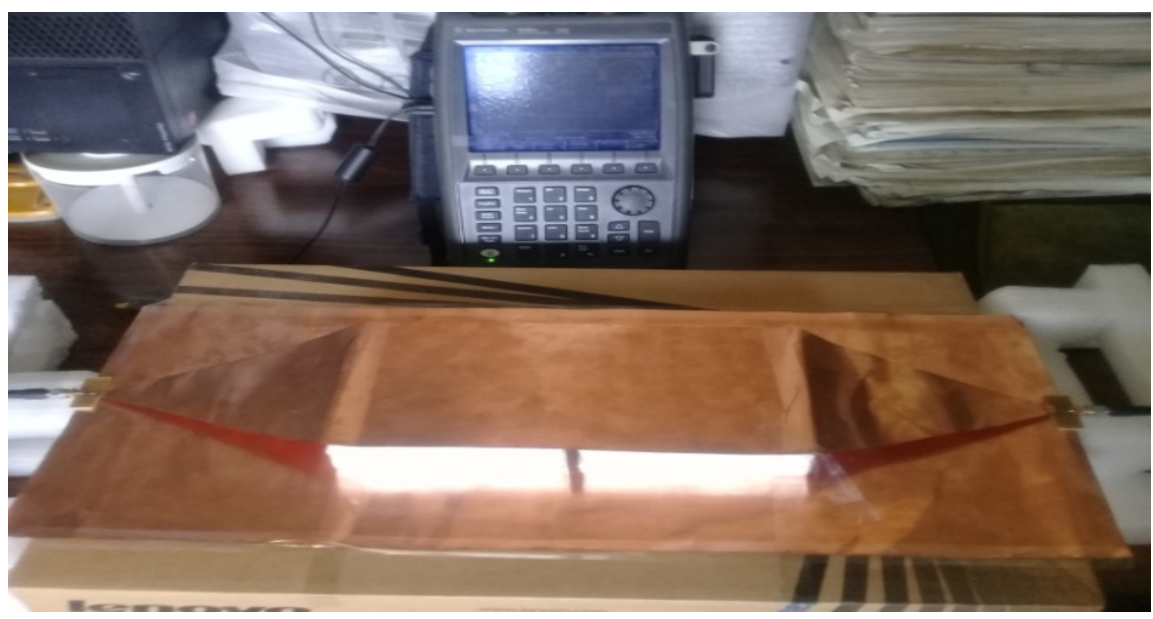

Figure 8. Fabricated TEM cell.

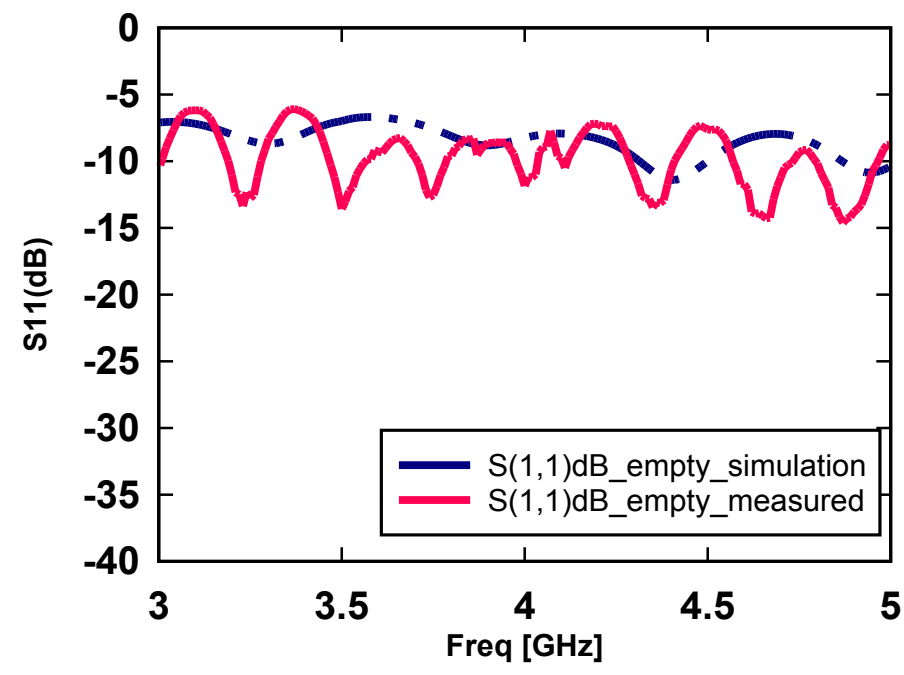

Figure 9. Simulated and measured $\mathrm{S}_{11}$ of the designed TEM cell. 


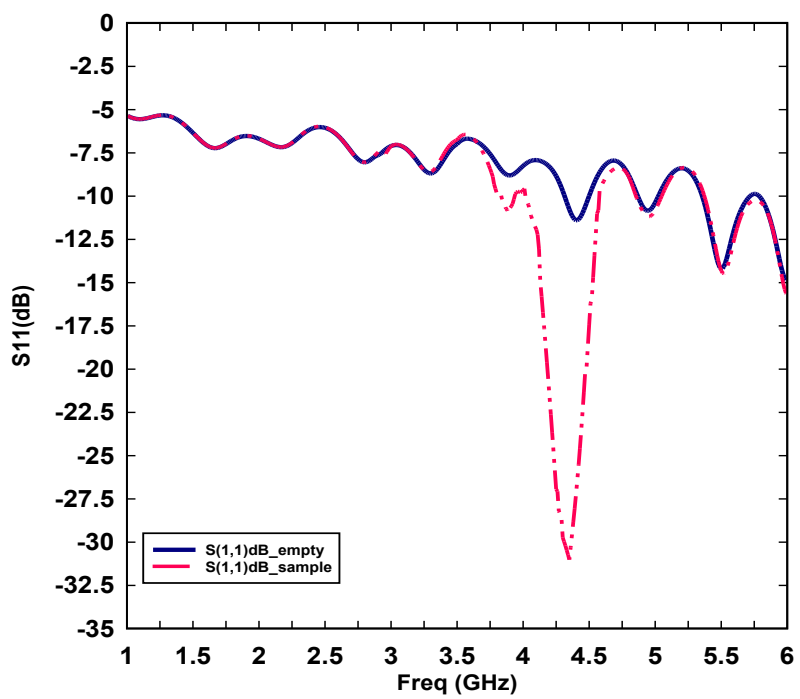

Figure 10. Comparison between $S_{11}$ of the TEM cell with and without the absorbing tile (Simulated results).

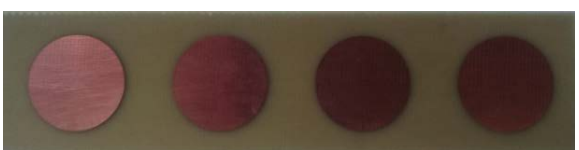

(a)

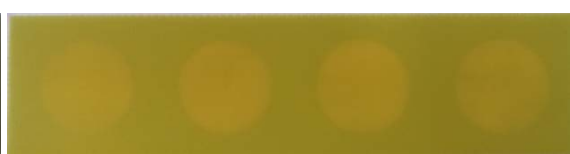

(b)

Figure 11. Fabricated sample absorbing tile for TEM cell measurements. (a) The array of circular patches; (b) The array of patches covered by a superstrate.

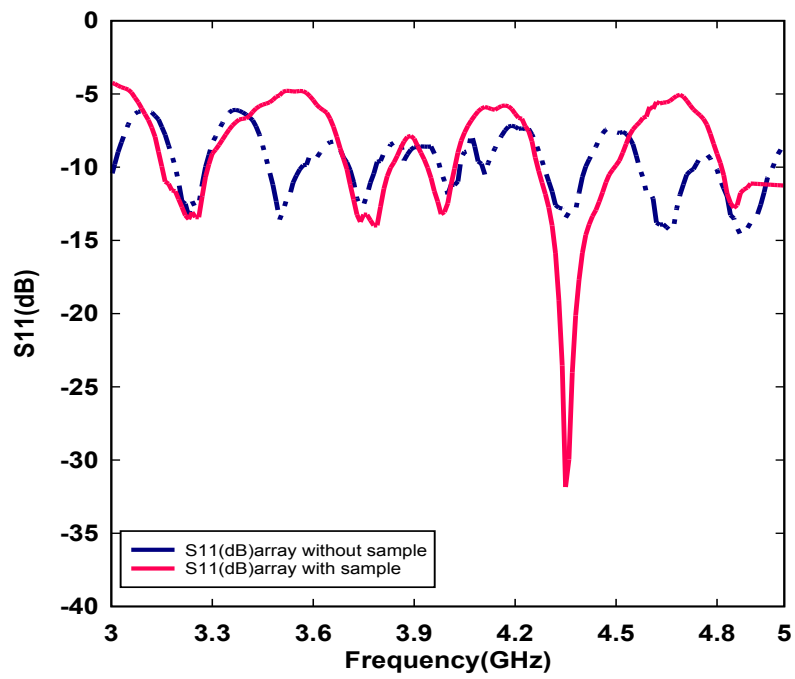

Figure 12. Comparison between $S_{11}$ of the TEM cell with and without the absorbing tile. (Measured results).

and covered by another lossy superstrate. Both the substrate and the superstrate are FR-4. The absorption frequency is controlled by the shape and the size of the patches. Periodicity is another important factor in controlling the absorption frequency. However, this factor is kept constant in the present study. Different shapes of the patches are studied including square, hexagonal and circular 
patches. The design procedure starts with simulation of an infinite array structure by using a single element inside periodic boundary conditions. Then the RCS of a finite tile of the designed array of patches is compared to the RCS of a PEC tile. The difference between these two values of the RCS corresponds to the difference between the digit " 1 " and " 0 " at the corresponding absorption frequency. Each shape shows a good behavior at specific frequencies. An experimental verification for the design of these absorbers is present for the case of circular patches by using TEM cell. The design of this TEM cell is also discussed in detail. Excellent agreements between simulated and experimental and simulated results are obtained.

\section{References}

[1] Roberts, C.M. (2006) Radio Frequency Identification (RFID). Computers \& Security, 25, 18-26. https://doi.org/10.1016/j.cose.2005.12.003

[2] Miles, S.B., Sarma, S.E. and Williams, J.R. Eds. (2008) RFID Technology and Applications. Vol. 1, Cambridge University Press, Cambridge.

https://doi.org/10.1017/CBO9780511541155

[3] Chang Ir, C.S. and Tsang, I.D.K. (2008) A Cost Effective Approach on Railway Vehicle Identification and Positioning Using RFID Technology. IET2nd International Conference on Wireless, Mobile and Multimedia Networks (ICWMMN 2008), 490-493. https://doi.org/10.1049/cp:20081043

[4] Zhang, X., Lakafosis, V., Traille, A. and Tentzeris, M.M. (2010) Performance Analysis of "Fast-Moving" RFID Tags in State-of-the-Art High-Speed Railway Systems. IEEE International Conference on RFID-Technology and Applications (RFID-TA), Guangzhou, 17-19 June 2010, 281-285. https://doi.org/10.1109/RFID-TA.2010.5529918

[5] Gupta, A.K., Katiyar, S. and Kumar, N. (2013) Railway Track Finding System with RFID Application. International Journal of Computer Applications, 83, No. 7.

[6] Leena, G., Vidawat, C.S. and Jha, N. (2017) Automatic Railway System. International Journal of Computer Applications, 159, No. 8.

[7] Lee, T. and May, T. (2016) A Universal Sensor Data Platform Modelled for Realtime Asset Condition Surveillance and Big Data Analytics for Railway Systems: Developing a "Smart Railway" Mastermind for the Betterment of Reliability, Availability, Maintainability and Safety of Railway Systems and Passenger Service. SENSORS, Orlando, FL, 30 October-3 November 2016, 1-3. https://doi.org/10.1109/ICSENS.2016.7808734

[8] Szprynger, W. (2016) Device for Receiving, Processing and Generating Signals for Automatically Controlling a Rail Vehicle. U.S. Patent 9428203, Issued August 30.

[9] Butani, P., John, J. and Dhole, A. (2007) Automatic Vehicle Identification Using RFID-A Firsthand Experience. Indian Railway Technical Bulletin (IRTB), 13, 1-16.

[10] Pandit, A.A., Mundra, A.K. and Talreja, J. (2009) RFID Tracking System for Vehicles (RTSV). First International Conference on Computational Intelligence, Communication Systems and Networks, CICSYN09, Indore, 23-25 July 2009, 160-165. https://doi.org/10.1109/CICSYN.2009.50

[11] Preradovic, S. and Karmakar, N. (2011) Fully Printable Chipless RFID Tag, Advanced Radio Frequency Identification Design and Applications. Dr Stevan Preradovic (Ed.), InTech. https://doi.org/10.5772/14555 
[12] Preradovic, S., Balbin, I., Karmakar, N.C. and Swiegers, G.F. (2009) Multiresonator-Based Chipless RFID System for Low-Cost Item Tracking. IEEE Transactions on Microwave Theory and Techniques, 57, 1411-1419. https://doi.org/10.1109/TMTT.2009.2017323

[13] Ishii, Y., Masaki, T., Michishita, N., Morishita, H. and Hada, H. (2016) RCS Reduction Characteristics of Thin Wave Absorbers Composed of Flat and Curved Metasurfaces. International Symposium on Antennas and Propagation (ISAP), Okinawa, 24-28 October 2016, 192-193.

[14] Okawa, H. and Nishikata, A. (2014) EM-Wave Absorber Composed of Periodic Patch Antennas Designed for Both H-and V-Polarized Waves at $2.4 \mathrm{GHz}$ Band. International Symposium on Electromagnetic Compatibility, Tokyo (EMC'14/Tokyo), Tokyo, 12-16 May 2014, 769-772.

[15] Shinohara, J., Michishita, N., Yamada, Y. and Hada, H. (2012) Thin Wave Absorber Composed of Mushroom Structures. International Symposium Antennas and Propagation Society (APSURSI), Chicago, IL, 8-14 July 2012, 1-2. https://doi.org/10.1109/APS.2012.6348043

[16] Bhattacharyya, S., Ghosh, S. and Srivastava, K.V. (2013) Bandwidth Enhanced Metamaterial Absorber Using Electric Field-Driven LC Resonator for Airborne Radar Applications. Microwave and Optical Technology Letters, 55, 2131-2137. https://doi.org/10.1002/mop.27786

[17] Yildiz, C., Demirel, G. and Çalişkan, F. (2015) Designing Transverse Electromagnetic (TEM) Cell. The 3 rd Electromagnetic Compatibility Conference EMC TURKIYE. 